Ansicht bestimmen, sind : 1) das verschiedene Verhalten beider Stoffe gegen Alkohol; 2) die Unlöslichkeit des Stoffes aus Holz in kochendem Wasser; 3) die Verschiedenheit des Niederschlags aus einer Lösung in überschüssigem Alkali; 4) liefert der aus Holz dargestellte Stoff bei dem Kochen mit Salpetersäure keine Schleimsäure. Endlich stimmt die von mir gefundene Zusaminensetzung nicht mit derjenigen der Pectinsäure überein.

\title{
Vorläufige Notiz über die Einwirkung der Wärme auf den Amylalkohol.
}

Capitain Reynolds hat in meinem Laboratorium die Producte studirt, in welche der Amylalkohol unter dem Einfluls höherer Temperalur zerfiilt. Es entstehen verschiedene gasförmige Körper; das Hauptproduct ist cin Gas, das bei der Berührung mil Chlor und Brom dic beiden Verbindungen :

$$
\begin{array}{lll}
\mathrm{C}_{6} & \mathrm{H}_{6} & \mathrm{Cl}_{2} \\
\mathrm{C}_{6} & \mathrm{H}_{6} & \mathrm{Br}_{2}
\end{array}
$$

liefert, welche den Fliissigkeiten, die aus dem ölbildenden Gase entstehen, in jeder Beziehung correspondiren. l)as obige Gas ist demnach der Kohlenwasserstoff, welcher zwischen dem ölbildenden Gase und Faraday's Gase, welches neuerdings wieder von Kolbe bei der Electrolyse der Valeriansäure beobachtet wurde, in der Mitte liegt.

$\begin{array}{llll}\text { Oelbildendes Gas } & \text { Acclen } & \mathrm{C}_{4} & \mathrm{H}_{4} \\ & \text { Metaceten } & \mathrm{C}_{6} & \mathrm{H}_{6} \\ \text { F a rada y's Gas } & \text { Butyren } & \mathrm{C}_{8} & \mathrm{H}_{8} \\ & \text { Amylen } & \mathrm{C}_{30} & \mathrm{H}_{10} .\end{array}$

Die Delails dieser Untersuchung werden in einem späteren Hefte der Annalen mitgelheilt werden.

Dr. A. W. Hofmann. 